\title{
HYBRID COMPOSITE CABLE WITH STEEL COMPONENT AS A STRUCTURAL ELEMENT
}

\author{
D. Serdjuks ${ }^{1, *}$ and K. Rocens ${ }^{2}$ \\ ${ }^{1}$ Assistant Professor, Institute of Structural Engineering and Reconstruction, \\ Riga Technical University, Latvia \\ ${ }^{2}$ Professor, Institute of Structural Engineering and Reconstruction, \\ Riga Technical University, Latvia \\ *(Corresponding author: E-mail:dmitrijs@bf.rtu.lv)
}

Received: 26 September 2006; Revised: 24 August 2007; Accepted: 4 September 2007

\begin{abstract}
High strength composite cables with large specific strength and made of base of materials using carbon fiber reinforced plastics (CFRP), glass fiber reinforced plastics (GFRP) and Vectran, are widely used in construction industry. However, the use of a steel component enables the small elongation of the cable to be moderately increased, the brittleness decreased and the scope of application of high strength composite cables expanded respectively. Cable made of steel in combination with other materials such as CFRP, GFRP and Vectran, was studied and reported in this paper. Volumetric fraction of steel was within the limits of 0.1 to 0.7 . The inter-dependent relationship of external pressure per unit surface area of the distributed layer (due to the pressure of steel wire strands) of hybrid composite cable on the axial force and angle of steel wire strands twisting was estimated by engineering method of calculations. Tangential and radial stresses of the distributed layer and core of hybrid composite cable were obtained. It was shown that the angle of steel wire strands twisting should not exceed $20^{\circ}$ in the case when the distributed layer and core are made of GFRP and CFRP respectively. Relationship between materials and their content in hybrid composite cables with the steel component was considered. Hybrid composite cables with the steel component were considered as materials of several groups of cables in a prestressed saddle-shaped cable roof. Opportunity to decrease the displacements of composite saddle-shaped cable roof by the use of hybrid composite cables with steel component in several groups of cables was investigated and reported.
\end{abstract}

Keywords: Steel wire strands, fiber reinforced plastics, cable net, vertical displacements

\section{INTRODUCTION}

High strength materials such as FRCC and FRP possess potential for their application as construction materials in combination with the steel. Carbon fiber reinforced plastic (CFRP), glass fiber reinforced plastic (GFRP) and Vectran are examples of such materials. As construction materials they have the following advantages:

- high specific strength;

- good durability in aggressive surrounding;

- CFRP is adaptable to be used in structures not allowed to be magnetic or electrically conductive;

- low density.

However, CFRP, GFRP and Vectran have a number of disadvantages, limiting their application as construction materials. Relatively small elongation at break, probability of surface damages and increased cost are most significant imperfections of CFRP, GFRP and Vectran in comparison with the steel cables.

Small elongation at break significantly decreases safety of construction due to the probability of brittle failure during short time growing of the load. This disadvantage could be improved by adding of the steel component, which enables to increase reliability of the cable. Addition of the distributed layer, which could be made of glass fiber reinforced plastic (GFRP), significantly decreases the possibility of surface damages of CFRP in hybrid composite cable. 
So, the surface pressure of steel wire strands at the distributed layer and that of distributed layer at the core of hybrid composite cable should be evaluated together with the radial and tangential stresses in the distributed layer and core.

Increased cost of CFRP in comparison with the steel cables could be partially compensated by the application of CFRP in economic, from the point of view of material consumption, constructions. One of CFRP utilization in practice is its application as tendons for the cable bridges. Saddle-shaped cable roof is another potential example of CFRP application as a construction material. Saddle-shaped cable roof is a type of constructions where such high strength construction materials as CFRP could be used on the full scale, because nearly all the load bearing elements are tensioned. However, the most significant disadvantage of the saddle-shaped cable roofs supported by the tensioned cables is the increased compliance. One of the eventual methods to decrease the compliance of the cable roofs is using of the cables with the increased moduli of elasticity. Hybrid composite cable on the base of steel, CFRP, GFRP and Vectran can be considered as an example of such a cable (Figure 1).
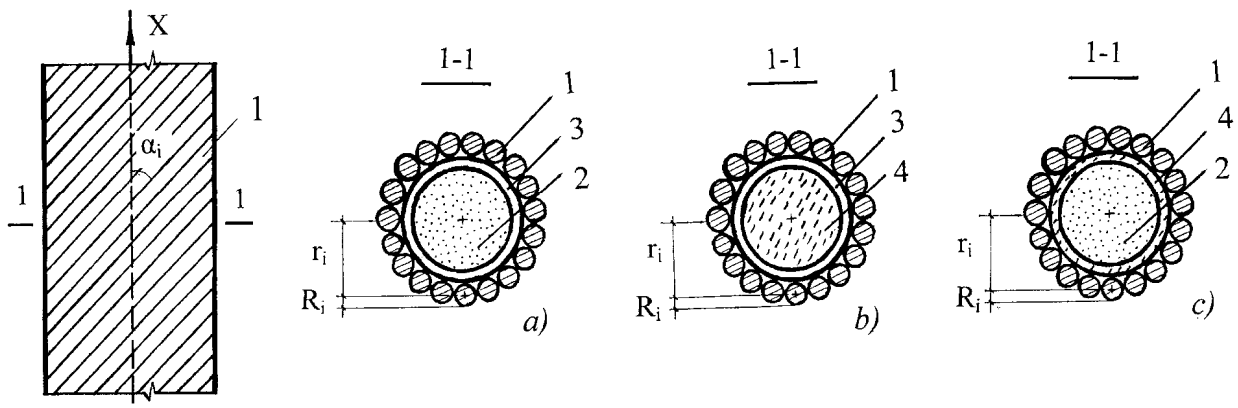

Figure 1. Hybrid Composite Cables on the Base of Steel, CFRP, GFRP and Vectran: 1 - Steel Component; 2 - CFRP Component; 3 - GFRP Component; 4 - Vectran Component; a) - Variant on the Base of Steel, GFRP and CFRP; b) - Variant on the Base of Steel, GFRP and Vectran;

c) - Variant on the Base of Steel, Vectran and CFRP; $\alpha_{i}$ - Angle of Steel Wire Strands Twisting;

$\mathrm{X}$ - Longitudinal Axis of the Cable; $r_{i}$ - Distance between the Center of

Separate Steel Wire Strand and Whole Cable; $\mathrm{R}_{\mathrm{i}}-$ Radius of Separate Steel Wire Strand

Another method is to use the cable trusses made of the materials with the increased moduli of elasticity as structures of the supporting contour of cable roof.

The purpose of this study is to consider behavior of hybrid composite cable on the base of steel, CFRP, GFRP, Vectran. Opportunity to decrease the displacements of the composite saddle-shaped cable roof by using of hybrid composite cables with the steel component for several groups of cables should be investigated.

\section{EVENTUAL MATERIALS COMBINATIONS FOR HYBRID COMPOSITE CABLES}

The main directions of the considered hybrid composite cables application are prestressed nets of saddle-shaped roofs. Two types of hybrid composite cables have been investigated. First of them is a hybrid composite cable with an increased, in comparison with the CFRP, ultimate elongation and decreased, in comparison with the steel, dead weight. This type of the cables could be used for the tension and suspension cables forming the prestressed nets. Second is a hybrid composite cable with relatively high ultimate elongation for the stressing cables of the prestressed nets. 
Combination of high strength and increased ultimate elongation is the main requirement for the first hybrid composite cable type. But the second type, unlike the first, should possess first of all, an increased ultimate elongation.

Thus, the first cable type should obligatorily contain two kinds of materials: one material with a large limit of strength and the other with an increased ultimate elongation. The third type of materials should be added to transfer pressure of the external layer to the surface of the internal one which is perpendicular to the direction of axial force action.

Steel wire strands can be treated as a material with an increased up to $10 \%$ ultimate elongation for the first type of the cable. Properties of GFRP (E-glass and epoxy matrix at $60 \%$ fiber content), CFRP (AS4/3501-6 graphite fibers and epoxy matrix at a 60\% fiber content), Vectran HS 1500 and strands of steel wire are indicated in Table 1 (e.g. Beers and Ramirez [1]; Bengtson [2]; Berger [3]; Blum [4]; Houtman [5] and Peters [6]).

Table 1. Mechanical Properties of Hybrid Composite Cables Components

\begin{tabular}{|c|c|c|c|}
\hline $\begin{array}{c}\text { Components of } \\
\text { hybrid } \\
\text { composite cabes }\end{array}$ & $E, \mathrm{MPa}$ & $R_{u}, \mathrm{MPa}$ & $\varepsilon_{u}, \%$ \\
\hline Steel wire strands & 200000 & 1900 & 10 \\
\hline GFRP & 75000 & 760 & 2.64 \\
\hline CFRP & 137000 & 2100 & 1.6 \\
\hline Vectran & 65000 & 2850 & 3.3 \\
\hline
\end{tabular}

* In Table 1 moduli of elasticity $\mathrm{E}$, limits of strength $\mathrm{R}_{\mathrm{u}}$, and breaking elongations $\varepsilon_{\mathrm{u}}$ are given in the longitudinal direction $\mathrm{X}$.

Based on the materials properties given in Table 1, two following material combinations can be considered for the first type of hybrid composite cable: steel, GFRP, CFRP and steel, Vectran, CFRP.

Second type of the cables should be based on the material with the increased ultimate elongation and limit of strength, which is enough to take up tension forces, acting in the stressing cables of the net. Combination of steel, Vectran and GFRP, probably, enables to obtain hybrid composite cables with such properties.

\section{EVALUATION OF MECHANICAL INTERACTION BETWEEN COMPONENTS IN HYBRID COMPOSITE CABLE}

\subsection{Approach to the Solution of the Problem}

Hybrid composite cable is considered as a system of two cylinders (Figure 2). Steel wire strands are replaced by the external pressure $p_{b}$ per unit of external surface area of the GFRP distributional layer.

The GFRP distributed layer is considered as a hollow cylinder inside which another cylinder, i.e., CFRP core is situated. The GFRP distributional layer has constant internal and external radii: $a$ and $b$, respectively. The CFRP core has constant external radius, which is equal to $a$.

Interaction between the GFRP distributed layer and CFRP core is considered as a pressure $p_{a}$ per unit of the surface area of the CFRP core or per unit of internal surface area of the GFRP distributed layer. 


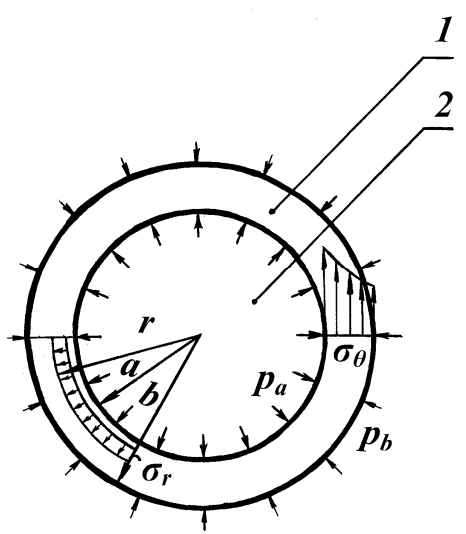

Figure 2. Scheme for Determination of Pressure at the CFRP core of Hybrid Composite Cable: $1-$

GFRP Distributed Layer; 2 - CFRP Core; $\sigma_{r}$ - Radial Stresses; $\sigma_{\theta}-$ Tangential Stresses; $p_{b}-$

External Pressure Per Unit of the Surface Area of the GFRP (Due to the Pressure of Steel Wire Strands); $p_{a}-$ External Pressure Per Unit of the Surface Area of the CFRP (Due to the Pressure of GFRP); $a$ - Radius of the CFRP Core of the Cable and Internal Radius of GFRP Distributed Layer; $b-$ External Radius of the GFRP Distributed Layer

Interaction between the GFRP distributed layer and CFRP core is considered as a pressure $p_{a}$ per unit of the surface area of the CFRP core or per unit of internal surface area of the GFRP distributed layer.

Pressure $p_{b}$ per unit of external surface area of the GFRP distributed layer could be determined by the following equation:

$p_{b}=-\frac{n \operatorname{tg}^{2} \alpha_{i}}{2 \pi a R}$

where: $n$-part of axial force $N$, which takes up steel wire strands of the cable; $\alpha_{i}-$ angle of steel wire strands twisting; $a$-radius of the CFRP core; $R$ - radius of the cable.

Eq. 1 was obtained for the case, when GFRP distributed layer limits the displacements of the steel wire strands in the radial direction. Pressure $p_{a}$ per unit of the surface area of the CFRP core and per unit of internal surface area of the GFRP distributed layer could be determined by the Eq. 2 . The Eq. 2 is obtained due to the equal radial deformations of CFRP core and GFRP distributed layer:

$\frac{1-v_{G r x}}{E_{G r}} \frac{p_{a} a^{2}-p_{b} b^{2}}{b^{2}-a^{2}} r+\frac{1+v_{G r x}}{E_{G r}} \frac{a^{2} b^{2}\left(p_{b}-p_{a}\right)}{\left(b^{2}-a^{2}\right) r}+\delta_{G r}=\frac{1-v_{C r x}}{E_{C r}} p_{a} r+\delta_{C r}$,

where $E_{G r}, E_{C r}=$ modulus of elasticity for GFRP and CFRP, respectively, in the radial directions; $r$ $=$ coordinate of the point, where deformations are determined; $v_{G r x}=$ Poisson's ratio of GFRP; $v_{C r x}$ $=$ Poisson's ratio of CFRP; $a=$ radius of the CFRP core of the cable and internal radius of GFRP distributed layer; $b$ - external radius of the GFRP distributed layer; $\delta_{G r}=$ radial deformations of GFRP due to the part of axial force, acting in the GFRP component of the cable; $\delta_{C r}=$ radial deformations of CFRP due to the part of axial force, acting in the CFRP component of the cable.

The left and right parts of the Eq. 2 are radial deformations of GFRP and CFRP components, respectively, due to the pressures $p_{b}$ and $p_{a}$. Radial deformations of GFRP and CFRP components $\delta_{G r}$ and $\delta_{C r}$ due to the parts of axial force, acting in the components also are taken into account. 
Values of radial deformations of GFRP and CFRP components $\delta_{G r}$ and $\delta_{C r}$ were determined basing on the consumption that components work in the elastic stage. Radial and tangential stresses act in the GFRP and CFRP due to the pressure $p_{b}$. The values of radial and tangential stresses could be determined by the equations which were obtained for the cylinder with the hole in the center, which is loaded by uniformly distributed by the internal and external surfaces pressures $p_{a}$ and $p_{b}$, respectively.

$$
\begin{gathered}
\sigma_{G r}=\frac{a^{2} b^{2}\left(p_{b}-p_{a}\right)}{\left(b^{2}-a^{2}\right)} \frac{1}{r^{2}}+\frac{p_{a} a^{2}-p_{b} b^{2}}{b^{2}-a^{2}}, \\
\sigma_{G \theta}=-\frac{a^{2} b^{2}\left(p_{b}-p_{a}\right)}{\left(b^{2}-a^{2}\right)} \frac{1}{r^{2}}+\frac{p_{a} a^{2}-p_{b} b^{2}}{b^{2}-a^{2}},
\end{gathered}
$$

where $\sigma_{G r}$ and $\sigma_{G \theta}=$ stresses acting in the GFRP component of hybrid composite cable in the radial and tangential directions.

For determination of radial and tangential stresses acting in the CFRP component of the hybrid composite cable, the following equation could be used:

$$
\sigma_{C r}=-p_{a}=\sigma_{C \theta},
$$

where: $\sigma_{C r}$ and $\sigma_{C \theta}=$ stresses acting in the CFRP component of hybrid composite cable in the radial and tangential directions.

Eq. 5 was obtained from the Eq. 3 and 4 when the internal radius of the cylinder (CFRP core) is equal to zero, external radius of the cylinder is equal to $a$, and external pressure per unit of the surface area of the CFRP (due to the pressure of GFRP) is equal to $p_{a}$.

\subsection{Determination of Pressures on the Components of Hybrid Composite Cables}

The relationship between the pressure at the CFRP core of hybrid composite cable and the axial force $N$ and angle of wire twisting $\alpha$ was developed by the example of tension cable of saddle-shaped cable roof with dimensions in plan 30x30m.

Cable, which is loaded by the uniformly distributed load, is considered as a scheme for analysis. From the point of view of materials consumption, the cable has rational initial deflection $f_{1}=5.7 \mathrm{~m}$. The uniformly distributed load with intensity $q=21 \mathrm{kN} / \mathrm{m}$ loads the cable (Figure 3 ).

Poisson's ratios in radial direction of GFRP and CFRP are equal to 0.05, 0.014, respectively. Limits of strength of GFRP and CFRP in radial direction are equal to 78 and $186 \mathrm{MPa}$, respectively.

The values of moduli of elasticity correspond to the elastic stages of the materials work. Volume fractions of fibers in GFRP and CFRP are 0.6. The fibers are oriented in the direction of axial force action. Volume fractions of steel wire, GFRP and CFRP are $0.4 ; 0.2$ and 0.4 , respectively. Total area of cross sections for hybrid composite cable was equal to $0.001 \mathrm{~m}^{2}$.

The value of the axial force $N$, acting in the cable due to the uniformly distributed load, was determined in two stages. First it was evaluated by the approximate method. Than the value of axial force was adjusted by the computer program "ANSYS/ED 5.3" with taking into account elastic elongation of the cable. 


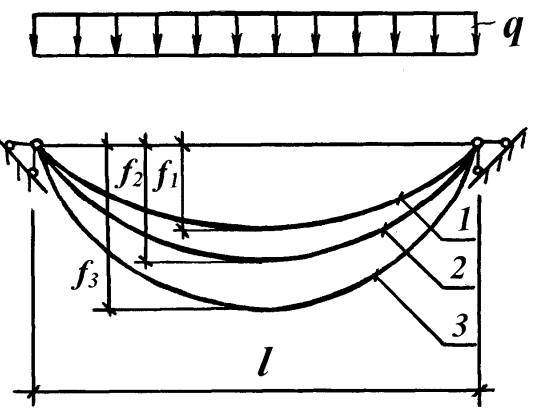

Figure 3. Scheme of Hybrid Composite Cable Work: 1 - Steel Wire, GFRP and CFRP Work Commonly; 2 - GFRP is Excluded from the Work; 3 - GFRP with CFRP are Excluded from the Work and Steel Wire Works Alone; $q$ - Design Vertical Load, Acting at the Cable; $f_{1}$ - Deflection of the Cable, which Corresponds to the Stage, when Steel Wire, GFRP and CFRP Work Commonly; $f_{2}$

- Deflection, which Corresponds to the Stage, when GFRP is Excluded from the Work and Steel Wire Works Commonly with CFRP; $f_{3}$ - Deflection, which Corresponds to the Stage, when GFRP and CFRP are Excluded from the Work and Steel Wire Works Alone; $l$ - Span of the Cable

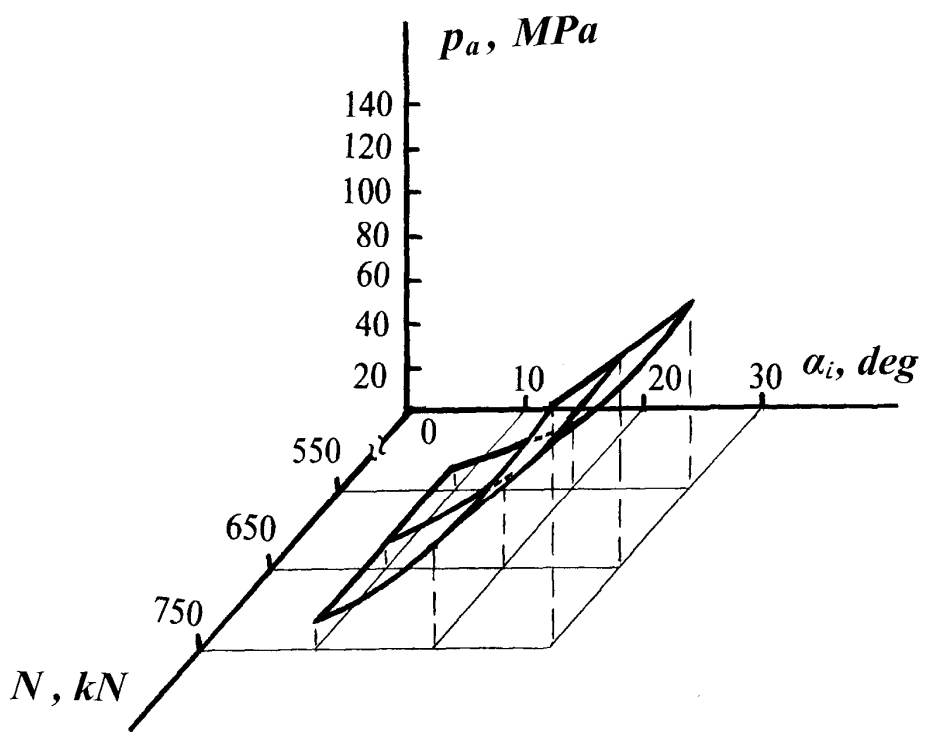

Figure 4. Relationship between the Pressure $p_{a}$, Axial Force $N$ and Angle of Steel Wire Strands Twisting $\alpha_{i}$.

Relationship between the pressure $p_{a}$, axial force $N$ and angle of steel wire strands twisting $\alpha_{i}$ is shown in Figure 4. The upper limit of the axial force is equal to $750 \mathrm{kN}$ because with the further growing of the axial force the GFRP component of the cable is excluded from the work. The value of the axial force $N$, acting in the cable, changes within the limits of 550 to $750 \mathrm{kN}$.

\subsection{Determination of Radial and Tangential Stresses, Acting in the Components of Hybrid Composite Cable}

Relationship between the maximum radial $\sigma_{C r}$, tangential stresses $\sigma_{C \theta}$, acting in the CFRP component of the hybrid composite cable and the axial force $N$ is shown in Figure 5. 


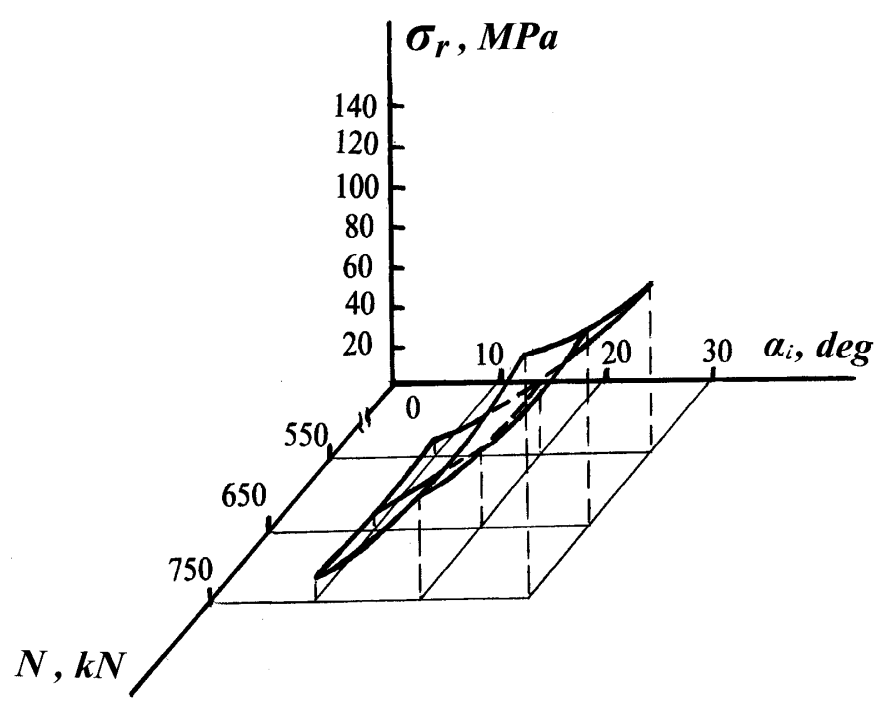

Figure 5. Relationship between the Radial $\sigma_{\mathrm{Cr}}$, Tangential $\sigma_{\mathrm{C} \theta}$ Stresses Acting in the CFRP and the Axial Force $\mathrm{N}$ and Angle of Steel Wire Strands Twisting $\alpha_{i}$

The values of the radial and tangential stresses are equal for the CFRP component of hybrid composite cable.

Comparison of the maximum radial stresses $\sigma_{C r}$, acting in the CFRP components of the hybrid composite cable with their strengths shows that the stresses are 1.65 times less, than the strength values, but the maximum values of tangential stresses $\sigma_{C \theta}$ are 13.79 times less, than the strength value. Maximum values of radial stresses were compared with the compression strength of CFRP in the direction perpendicular to the direction of fiber orientation, which is equal to $186 \mathrm{MPa}$. Tangential stresses were compared with the compression strength of CFRP in the direction corresponding to that of fiber orientation, which is equal to $1558 \mathrm{MPa}$.

The maximum values of radial $\sigma_{G r}$ and tangential $\sigma_{G \theta}$ stresses acting in the GFRP component of hybrid composite cable are given in Table 2 depending on the angle of steel wire strands twisting $\alpha_{i}$. The maximum values of radial and tangential stresses were obtained when the axial force $N$, acting in the cable, was equal to $750 \mathrm{kN}$ and $r=a$.

Table 2. Maximum Radial and Tangential Stresses, Acting in the GFRP Component of Hybrid Composite Cable

\begin{tabular}{|c|c|c|}
\hline $\begin{array}{c}\text { Angle of steel wire } \\
\text { strands twisting } \\
\alpha_{i}, \mathbf{,}\end{array}$ & $\sigma_{G r}, \mathrm{MPa}$. & $\sigma_{G \theta}, \mathrm{MPa}$. \\
\hline 10 & 10.77 & 21.29 \\
\hline 20 & 45.02 & 44.85 \\
\hline 30 & 114.81 & 93.32 \\
\hline
\end{tabular}

Comparison of the maximum tangential and radial stresses, acting in the GFRP components of the hybrid composite cable with their strengths shows, that the maximum angle of steel wire strands twisting for the considered case is $20^{\circ}$, when the radial stresses are equal to $45.02 \mathrm{MPa}$, which are 1.73 times less than the strength value. 


\section{EVALUATIONS OF MECHANICAL PROPERTIES OF HYBRID COMPOSITE CABLES}

\subsection{Evaluation of Modulus of Elasticity of Hybrid Composite Cables}

Let us to determine behaviors of three variants of hybrid composite cables. The behaviors of hybrid composite cables are defined by the dependence of proportional components summing on the base of behaviors of separate components.

Generally known dependence of proportional components summing was used for the engineering evaluation of modulus of elasticity of the hybrid composite cable. The dependences are given for the variant of the hybrid composite cable on the base of steel, GFRP and CFRP.

$E=\Omega_{C} E_{C}+\left(1-\Omega_{C}-\Omega_{S}\right) E_{G}+\Omega_{S} E_{S}$,

where

$$
\begin{aligned}
& \Omega_{C}=\frac{A_{C}}{A}, \Omega_{S}=\frac{A_{S}}{A}, \\
& E_{S}=\frac{\sum_{i=1}^{n} m_{i} A_{i} E_{i} \sin \left(90-\alpha_{i}\right)\left[1-(1+v) p_{i} \cos ^{2} \alpha_{i}\right]}{A_{S}}, \\
& A_{i}=\pi r_{0}^{2} \\
& p_{i}=\left(1-v \frac{R_{i}}{r_{i}} \cos ^{2}\left(90-\alpha_{i}\right)\right) \times \\
& {\left[1-\frac{R_{i}^{2}}{4 r_{i}^{2}}\left(1-\frac{v}{1+v} \cos ^{2}\left(90-\alpha_{i}\right)\right) \cos ^{2}\left(90-\alpha_{i}\right)\right],}
\end{aligned}
$$

where: $E=$ modulus of elasticity of hybrid composite cable; $A=$ cross-sectional area of hybrid composite cable; $A_{C}, A_{S}=$ cross-sectional areas of CFRP and steel components, respectively; $E_{C}$, $E_{G}, E_{S}=$ moduli of elasticity of CFRP, GFRP and steel components, respectively; $m_{i}=$ amount of steel wires in the $\mathrm{i}$-th strand; $A_{i}=$ cross-sectional area of the separate steel wire in the $\mathrm{i}$-th strand; $r_{0}$ $=$ radius of separate steel wire; $E_{i}=$ modulus of elasticity of steel wire; $\alpha_{i}$ - angle of $\mathrm{i}$-th steel wire strands twisting; $v=$ Poison's ratio of steel wire; $R_{i}=$ radius of $\mathrm{i}$-th steel wire strand; $r_{i}=$ distance between the centers of $\mathrm{i}$-th steel wire strand and cable.

Modulus of elasticity of the steel component of the hybrid composite cable was evaluated by the method of Cumar and Cochran (e.g. Costello [7]; e.g. Cumar and Cochran [8]).

\subsection{Character of Deformations of Hybrid Composite Cables}

The relationship between the strain $\varepsilon$ and the force $N$, acting in the cable, was obtained for three variants of composite cables with the area of cross-sections equal to $0.001 \mathrm{~m}^{2}$. Empty space was not taken into account. The relationship was obtained on the base of stress-strain curves of separate components (e.g. Beers [1], Bengtson [2] and Peters [6]). Following consumptions were considered. The steel wire and GFRP are working in the elastic stage till the strains, which are equal to 0.95 and $1 \%$, respectively. Then occurs yielding till the ultimate strains of 10 and $2.64 \%$, respectively. The CFRP and Vectran components are working in the elastic stage till the ultimate strains of 1.6 and $3.3 \%$, respectively. 
Volumetric fraction of steel for each variant changes within the limits of 0.1 to 0.7 . Volume fractions of GFRP in the two first variants and Vectran in the third variant of hybrid composite cables were constant and equal to 0.2. Angle of steel wire strands twisting was adopted equal to 12 degrees on the base of the previous investigations and literature recommendations.

The relationship between the strain $\varepsilon$ and the force $N$, acting in the cable, for hybrid composite cable on the base of steel, GFRP and CFRP is shown in Figure 6.

The relationship illustrates, that increase of volumetric fraction of steel from 0.1 to 0.7 enables the increase by $20.4 \%$ the value of the force, which can be taken up by the cable. The value of the force corresponds to $0.95 \%$ value of the strain. Modulus of elasticity of the cable grows from $1.25 \cdot 10^{5}$ to $1.57 \cdot 10^{5} \mathrm{MPa}$ at the same time.

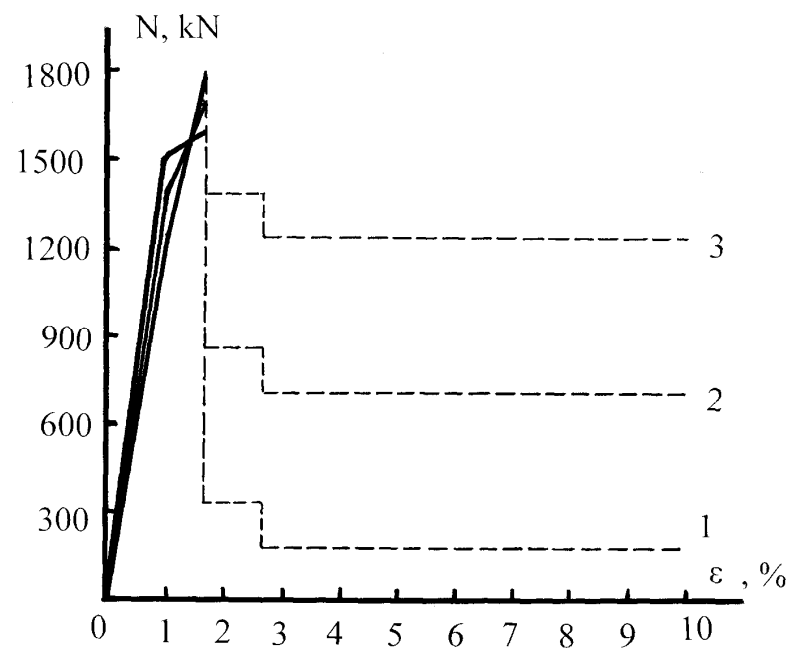

Figure 6. Strain of Hybrid Composite Cable on the Base of Steel, GFRP and CFRP $\varepsilon$ vs. the Force $\mathrm{N}$, Acting in the Cable: 1,2,3 - the Relationships, which were Obtained at Volumetric Fractions of

Steel, Equal to $0.1 ; 0.4 ; 0.7$, Respectively; (__ ) - Stage, when all the Components of the Cables Work Commonly; (------) - Stage, when some Components are Disrupted

The relationship between the strain $\varepsilon$ and the force $N$, acting in the cable, for hybrid composite cable on the base of steel, GFRP and Vectran is shown in Figure 7.

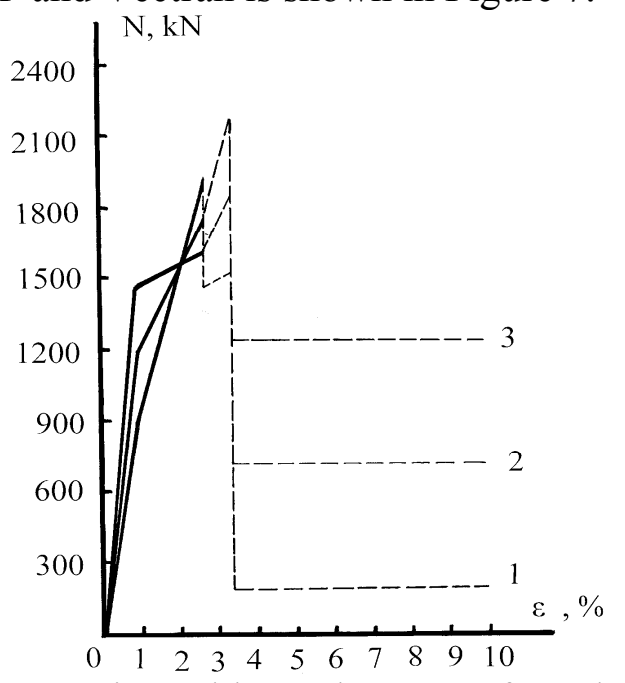

Figure 7. Strain of Hybrid Composite Cable on the Base of Steel, GFRP and Vectran $\varepsilon$ vs. the Force N, Acting in the Cable: 1,2,3 - the Relationships, which were Obtained at Volumetric Fractions of Steel, Equal to 0.1; 0.4; 0.7, Respectively; (- - Stage, when all the Components of the Cables Work Commonly; (------) - Stage, when some Components are Disrupted 
The relationship illustrates, that increase of the volumetric fraction of steel from 0.1 to 0.7 , increases by 1.63 times the value of the force, which can be taken up by the cable. Modulus of elasticity of the cable grows from $0.94 \cdot 10^{5}$ to $1.53 \cdot 10^{5} \mathrm{MPa}$ at the same time.

The relationship of strain $\varepsilon$ and the force $N$, acting in the cable, for the hybrid composite cable on the base of steel, Vectran and CFRP has a property which is analogous to the dependences shown in Figure 6 and Figure 7. The value of force, which can be taken up by the cable, changes from $1212.5 \mathrm{kN}$ to $1517.8 \mathrm{kN}$, when the volumetric fraction of steel changes from 0.1 to 0.7 . Modulus of elasticity of the cable grows from $1.27 \cdot 10^{5}$ to $1.6 \cdot 10^{5} \mathrm{MPa}$ at the same time.

Comparison of the relationships between the strain $\varepsilon$ and the force $N$ for three variants of hybrid composite cables indicates, that maximum strain $(2.64 \%)$ without any components disruption possesses a variant on the base of steel, GFRP and Vectran. But the value of the force, which can be taken up by the cable, is a minimum for all the variants and equals to $1453.6 \mathrm{kN}$. Variants on the base of steel, GFRP, CFRP and steel, Vectran, CFRP have increased values of the forces, which can be taken up by the cables -1496 and $1517.8 \mathrm{kN}$, respectively. But the values of maximum strains without any components disruption are equal to $1.6 \%$.

\section{STEEL COMPONENT IN HYBRID COMPOSITE CABLE FOR SADDLE-SHAPED ROOF}

Hybrid composite cable on the base of steel, CFRP, GFRP and Vectran was considered as a material for the tension and main diagonal suspension cables of the saddle shaped cable roof since characteristics of the cables have significant influence on the compliance of the structure (e.g. Serdjuks et al. $[9,10,11])$. The cable roof was square in plan with dimensions 50x50 m. The initial deflections of the suspension, stressing and tension cables were equal to 20 and $8.6 \mathrm{~m}$, respectively. The distance between the suspension and stressing cables was equal to $1.414 \mathrm{~m}$. The geometrical characteristics of the cable roof are rational from the point of view of materials consumption (e.g. Serdjuks et al. [12]).

The structure was calculated for the basic combination of loads - the dead weight of the structure $(0.27 \mathrm{kPa})$ and the weight of snow $(1.12 \mathrm{kPa})$ - evenly distributed on the horizontal projection of the roof. The design load in the form of point wise forces was applied to the nodes of the cable net. The roof had the following layers: a glass net coated with polymer resin $(2 \mathrm{~mm})$, foam plastic, reinforced with a glass net $(120 \mathrm{~mm})$, and saddle-shaped plywood sheets $(6 \mathrm{~mm})$.

The cable net was prestressed by applying tension forces to the suspension and stressing cables, such that the residual tension forces in the stressing cables were equal to $20 \%$ of their initial values under the vertical design load.

The maximum vertical displacements of the cable roof were determined by the computer program "ANSYS/ED 5.3". The existence of two symmetry planes allows us to regard, as a design scheme, a quarter of the cable net of the saddle-shaped cable roof with a compliant supporting contour (Figure 9). Three quarters of the cable roof were replaced by the bonds imposed on its one-quarter part. The cable net was modeled by the finite element of LINK 10 type, with three degree of freedom for each node. Steel cables with an elastic modulus of $1.3 \cdot 10^{5} \mathrm{MPa}$ were assumed as a material for the suspension and stressing cables, excluding the main diagonal ones. 
The relationships between the maximum vertical displacements of the cable net and the volumetric fraction of the steel component in the hybrid composite cables are shown in Figure 8. The relationships were obtained for the stages when all the components of the hybrid composite cables work commonly and when all the components, excluding the steel, were disrupted. Deformations of the cables for the all stages of work were taken into account.

In the case, when all the components of the hybrid composite cable work commonly, the increase of volumetric fraction of the steel from 0.1 to 0.7 causes the decrease of the maximum vertical displacements of the cable roof by 9.31 and $8 \%$ for the variants, when the hybrid composite cable is on the base of steel, GFRP and CFRP, steel, GFRP and Vectran and steel, Vectran and CFRP, respectively.

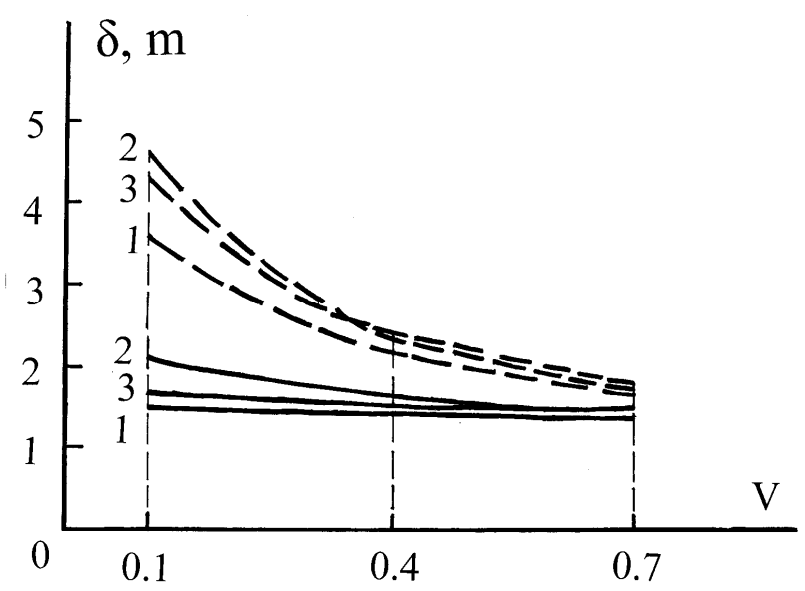

Figure 8. Relationship between the Maximum Vertical Displacements of the Cable Roof $\delta$ and the Volumetric Fraction of Steel in Hybrid Composite Cables V: 1- Variant on the Base of Steel, GFRP and CFRP; 2 - Variant on the Base of Steel, GFRP and Vectran; 3-Variant on the Base of Steel, Vectran and CFRP; (_- - - Stage, when all the Components of the Cables Work Commonly; (------) - Stage, when all the Components, Excluding the Steel, are Disrupted

In the case of emergency, when all the components, excluding the steel, are disrupted, the increase of volumetric fraction of the steel from 0.1 to 0.7 causes decrease of the maximum vertical displacements of the cable roof by $2.21,2.78$ and 2.46 times for the variants, when hybrid composite cable is on the base of steel, GFRP and CFRP, steel, GFRP and Vectran and steel, Vectran and CFRP, respectively.

The points with maximum vertical displacements of the cable roof are placed approximately in the quarter of the span. Deformed shape of the cable net is shown in Figure 9 (b). This stage of the cable roof works is characterized by the growing of vertical displacements and decrease of the axial forces, acting in the cables. The value of tension stresses, acting in the cables, does not exceed the limit of strength. The serviceability limit stage does not satisfied but the collapse of structure is prevented and evacuation can be organized normally.

Maximum vertical displacements of the cable roof are equal to $4.562 \mathrm{~m}$. The value is 1.9 times less, than the distance down to the surface of the ground. So, we can suppose that the steel component of hybrid composite cable can prevent failure of the cable roof in emergency, when the strain of CFRP, Vectran and GFRP exceeds the ultimate values and these components are disrupted. The using of CFRP, GFRP and Vectran components enables to decrease the dead weight of the cables by $44-47 \%$ when the volumetric fraction of steel is equal to 0.4 at the same time. 
a)

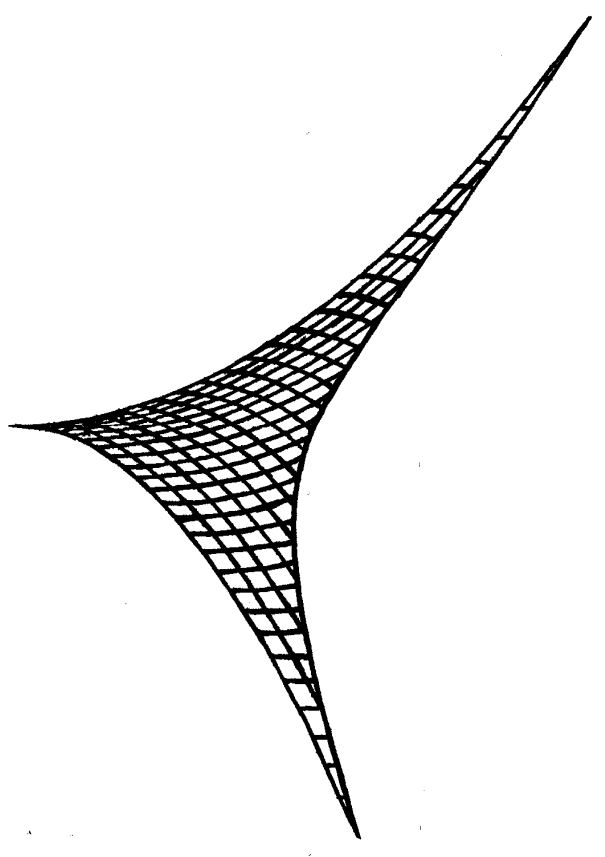

b)

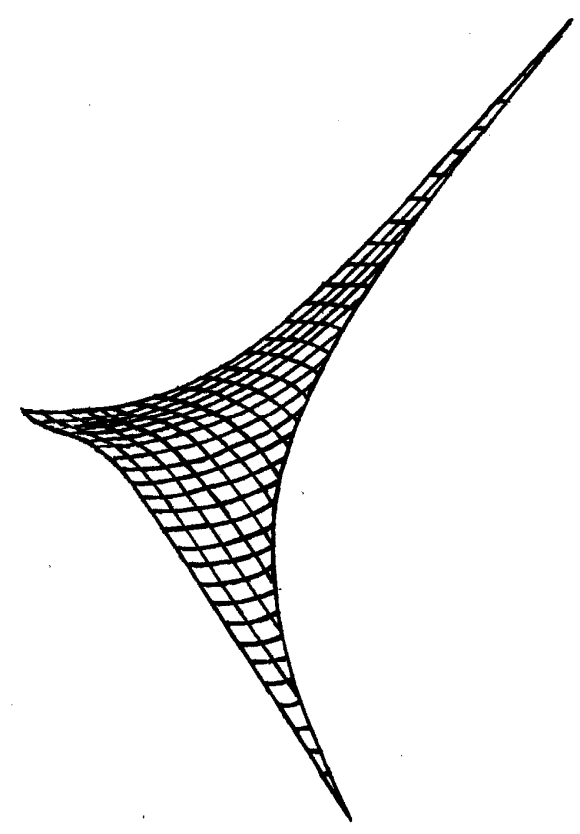

Figure 9. Deformed and Undeformed Shapes of Cable Net Quarter:

a) - Undeformed Shape; b) - Deformed Shape

Possibility to decrease the displacements of the composite saddle-shaped cable roof by using of cable trusses made of the material with the increased modulus of elasticity as structures of supporting contour was considered for the above mentioned example. Hybrid composite cable on the base of steel, GFRP and CFRP was considered as a material of cable truss together with the steel cables, which are considered as a material of suspension and stressing cables. Volumetric fractions of steel and CFRP were equal to 0.4. Volumetric fraction of GFRP was equal to 0.2. Quarter of the cable net with the cable truss as a structure of supporting contour is shown in Figure 10 together with the deformed shape of cable net, which is loaded by the design vertical load.

a)

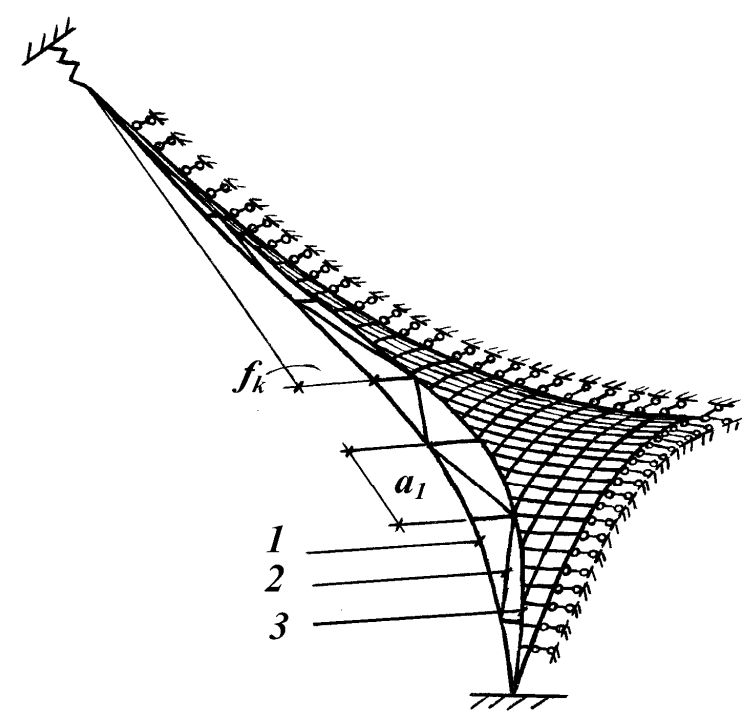

b)

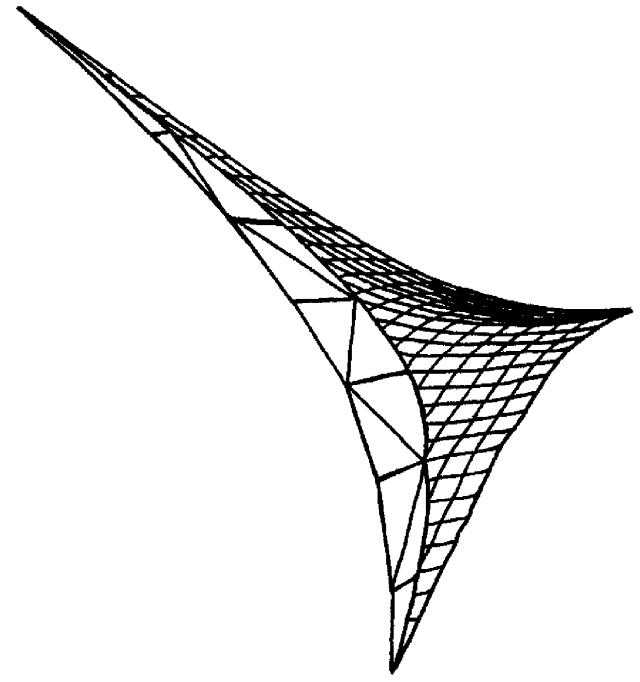

Figure 10. a) Quarter of Cable Net, Supported by Compliant Supporting Contour: 1 - Top Cable of Supporting Contour, 2 - Tie-bar, 3 - Bottom Cable of Supporting Contour, $\mathrm{f}_{\mathrm{k} 1}$ - Initial Deflection of Top Chord of Compliant Supporting Contour, $a_{1}-$ Distance between the Support Points of Tie-bars. b) Shape of Prestressed Cable Net after Vertical Design Load Application 
It was stated, that the minimum values of vertical displacements of cable net were obtained, when the initial deflection of top chord of cable truss were equal to $3.13 \mathrm{~m}$ and distance between the nodes of the cable truss was equal to $7 \mathrm{~m}$.

Application of hybrid composite cable as a material of supporting contour instead of steel enables to decrease by $1.3 \%$ maximum vertical displacements of the cable net. The using of the cable truss as a structure of support contour enables to decrease by $8 \%$ the maximum vertical displacements of the cable net in the case, when the tension cables of the net are hybrid composite cables, but suspension and stressing cables of the net are made of steel.

\section{CONCLUSIONS}

Hybrid composite cables on the base of steel, GFRP, CFRP and Vectran, which are differed by the components and volume fractions, were considered. The relationship between the external pressure per unit of the surface area of the GFRP (due to the pressure of steel wire strands) $p_{b}$ of hybrid composite cable and the axial force $N$ and angle of steel wire strands twisting $\alpha$ was obtained.

It was shown, that increasing of angle of steel wire strands twisting $\alpha_{i}$ from 10 to 30 degrees causes growing of external pressure per unit of the area of CFRP by 14.61 times when the axial force increases from 550 to $750 \mathrm{kN}$.

Tangential and radial stresses for GFRP and CFRP components of hybrid composite cable were obtained. It was shown, that the maximum angle of steel wire strands twisting $\alpha_{i}$ is equal to $20^{\circ}$ for the considered hybrid composite cable.

It was shown, that maximum radial stresses $\sigma_{G r}$ acting in the GFRP component of hybrid composite cable, when the angle of the steel wire strands twisting $\alpha_{i}$ was equal to $20^{\circ}$, and the axial force $N$ was equal to $750 \mathrm{kN}$, was 1.73 times less than the strengths of GFRP.

The relationship between strain $\varepsilon$ and the force $N$, acting in the cable, for hybrid composite cables on the base of steel, GFRP, CFRP and Vectran, which are differed by the components and volumetric fractions, were obtained. It was indicated that increase of volumetric fraction of steel from 0.1 to 0.7 enables to increase the value of the force, which can be taken up by the cable, by $20.4 \%$ for the cable on the base of steel, GFRP and CFRP; by $20.1 \%$ for the cable on the base of steel, Vectran and CFRP. Volumetric fractions of GFRP and Vectran were equal to 0.2. At the same time, increase of volumetric fraction of steel from 0.1 to 0.7 enables to increase the value of force, which can be taken up by the cable, by 1.63 times for the cable on the base of steel, GFRP and Vectran. Volumetric fraction of GFRP was equal to 0.2 .

The using of the cable truss as a structure of support contour enables to decrease by $8 \%$ the maximum vertical displacements of the cable net in the case, when the tension cables of the net are hybrid composite cables on the base of steel, GFRP and CFRP, but suspension and stressing cables of the net are made of steel. 


\section{REFERENCES}

[1] Beers, D.E. and Ramirez, J.E., "Vectran Fibers for Ropes and Cables", Proceedings of MTS Conference, Washington, 1990, pp. 662-670.

[2] Bengtson, A., "Fatigue Tests with Carbon-Fiber-Reinforced Composite Cable as Nonmetallic Reinforcement in Concrete", Göteborg, 1994, pp. 1-14.

[3] Berger, H., "Light Structures-Structures of Light: the Art and Engineering of Tensile Architecture", Birkhauser, Basel, 2002.

[4] Blum, R., "Material Propertiesof Coated Fabrics for Textile Architecture", Proceedings of the symposium The design of Membrane and Light Weight Structures, Brussel, 2000, pp. 63-88.

[5] Houtman, R., "There is no Material Like Membrane Material", Proceedings of the Tensinet Symposium Designing Tensile Architecture, Brussel, 2003, pp. 178-194.

[6] Peters, S.T. "Handbook of Composites", London, 1998. pp. 758-777.

[7] Costello, G.A., "Theory of Wire Rope, Second Edition”, New York, Springer, 1997.

[8] Kumar, K. and Cochran, Ir. I.E., "Closed form Analysis for Elastic Deformations of Multilayered Strands", Journal of Applied Mechanics, ASME, 1997, Vol. 54, pp. 898-903.

[9] Serdjuks, D., Rocens, K., and Pakrastinsh, L., "Utilization of Composite Materials in Saddle-Shaped Cable Roof", Mechanics of Composite Materials, 2000, Vol. 36, No. 5, pp. 385-388.

[10] Serdjuks, D., Rocens, K., "Hybrid Composite Cable Based on Steel and Carbon", Materials Science, 2000, Vol. 9, No. 1, pp. 27-30.

[11] Serdjuks, D., Rocens, K. and Mitrofanov, V., "Behavior of Hybrid Composite Cable in Saddle-Shaped Roof", Scientific Proceedings of Riga Technical University, Architecture and Construction Science, 2002, Vol. 3, pp. 162-169.

[12] Serdjuks, D., Rocens, K and Ozolinsh, R., "Influence of Diagonal Cables Strengthening by the Trusses on the Saddle-Shaped Roof Rigidity", Scientific Proceedings of Riga Technical University, Architecture and Construction Science, Vol. 6, pp. 210-218. 